\title{
Kegiatan Educhild Sebagai Upaya Peningkatan Kualitas Pendidikan dan Pembelajaran Pelajar TK, SD, dan SMP di Desa Bulak Kota Surabaya
}

\author{
Achda Atma A.K, ${ }^{1, *}$ Lisa Agustin, ${ }^{2}$ Nancy Nurinasari, ${ }^{3}$ Denny Oktavina Radianto ${ }^{4}$ \\ ${ }^{1}$ Manajemen Bisnis, Politeknik Perkapalan Negeri Surabaya, Surabaya, Indonesia \\ e-mail: *11azizahriris@gmail.com, ${ }^{2}$ lisaluhan222@gmail.com, ${ }^{3}$ nancynurinasari1@ gmail.com, \\ ${ }^{4}$ dennyokta@ppns.ac.id
}

\begin{abstract}
ABSTRAK Salah satu bentuk kegiatan pengabdian masyarakat adalah dengan menyelenggarakan kegiatan pembelajaran kepada masyarakat sekitar. Bentuk pengabdian masarakat yang dilakukan oleh Himpunan Mahasiswa Manajemen Bisnis Politeknik Perkapalan Negeri Surabaya adalah dengan melakukan kegiatan "Educhild". Kegiatan Educhild dilaksanakan di desa Bulak Kota Surabaya. Desa Bulak merupakan desa yang berada di wilayah pesisir kota Surabaya dengan sebagian besar penduduknya bermata pencaharaian sebagai nelayan. Strategi dan mekanisme dari pelaksanaan dari Educhild adalah persiapan, pelaksanaan, penutupan, dan evaluasi. Pola pengajaran yang digunakan dalam kegiatan Educhild adalah ; 1) Penetapan Tujuan dan Melakukan Perencanaan , 2) Pelaksanaan Kegiatan, 3) Problem Solving Section. Kegiatan Educhild yang telah dilakukan memberikan hasil berupa adanya peningkatan aktivitas pelajar dalam belajar dan antusiasme pelajar dalam mengerjakan dan menyelesaikan tugas rumah yang sangat besar. Siswa terlihat lebih aktif dan antusias dalam berkomunikasi, bertanya, menjawab, menyimpulkan, dan mengkomunikasikan temuannya. Kegiatan Educhild yang dilakukan di Desa Bulak Kota Surabaya bisa meningkatkan kualitas proses pembelajaran.
\end{abstract}

KATA KUNCI Pengabdian masyarakat; educhild; Desa Bulak.

ABSTRACT One form of community service activities is by organizing learning activities to the surrounding community. The form of community service carried out by the Business Management Student Association of Surabaya State Shipping Polytechnic is by conducting "Educhild" activities. Educhild's activities were held in the village of Bulak, Surabaya. Bulak Village is a village located in the coastal area of the city of Surabaya with the majority of its residents working as fishermen. The strategies and mechanisms of the implementation of Educhild are preparation, implementation, closure, and evaluation. The teaching pattern used in Educhild's activities is; 1) Determination of Goals and Planning, 2) Implementation of Activities, 3) Problem Solving Section. Educhild activities that have been carried out give results in the form of an increase in student activity in learning and student enthusiasm in working on and completing very large homework assignments. Students look more active and enthusiastic in communicating, asking questions, answering, concluding, and communicating their findings. Educhild activities conducted in Bulak Village, Surabaya City can improve the quality of the learning process.

KEYWORDS Community service; educhild; Bulak Village. 


\section{Pendahuluan}

Kegiatan pengabdian kepada masyarakat merupakan hal yang sangat penting untuk dilakukan oleh mahasiswa. Hal ini karena melalui kegiatan pengabdian masyarat mahasiswa dapat memberikan kontribusi nyata kepada masarakat sekitar dan memberikan ilmu - ilmu yang bermanfaat bagi masyarakat. Selain itu menurut Undang-Undang Nomor 12 Tahun 2012 pasal 1, disebutkan bahwa Tridharma Perguruan Tinggi yang selanjutnya disebut Tridharma adalah kewajiban Perguruan Tinggi untuk menyelenggarakan Pendidikan, Penelitian, dan Pengabdian kepada masyarakat. kegiatan pengabdian masyarakat termasuk salah satu dari tri dharma perguruan tinggi sehingga hal tersebut menjadi hal yang wajib dilakukan oleh mahasiswa. Sebagai mahasiswa, peneliti ingin memberikan melakukan tridharma perguruan tinggi yaitu dalam hal pengabdian masyarakat.

Salah satu bentuk kegiatan pengabdian masyarakat adalah dengan menyelenggarakan kegiatan pembelajaran kepada masyarakat sekitar. Kegiatan pembelajaran yang dilakukan peneliti adalah berupa pemberian berupa les yang diberikan secara gratis kepada anak - anak murid sekolah yang ada di Desa Bulak, Kenjeran, Surabaya Timur. Desa Bulak terletak di wilayah pesisir pantai Kenjeran. Sebagian besar penduduk wilayah desa Bulak memiliki pekerjaan sebagai nelayan. dalam desa tersebut tidak terdapat lembaga kursus pendidikan yang menyediakan jasa les kepada murid - murid sekolah yang ada di Desa Bulak. Sedangkan banyak penduduk di desa tersebut yang masih usia sekolah dan pasti membutuhkan kegiatan kegiatan pembejaran berupa les untuk membantu meningkatkan pehamaham mereka terhadap materi yang diajarkan di sekolah. Program kegiatan belajar mengajar berupa tambahan les bagi penduduk di Desa Bulak dinamakan program "Educhild". Kegiatan ini diselengarakan oleh Himpunan Mahasiswa Manajemen Bisnis Tahun 2018/2019 sebagai salah satu program dari divisi sosial masyarakat.

Adapun alasan peneliti memilih kegiatan pembelajaran sebagai bentuk kegiatan pengabdian masyarakat adalah karena hal tersebut termasuk dalam kegiatan peningkatan pendidikan. Sedangkan pendidikan sendiri merupakan salah satu dari upaya pembangunan nasional. Menurut Zain (dalam Jolinanda, 2016 :4) dalam pembangunan nasional, pendidikan diartikan sebagai upaya meningkatkan harkat dan martabat manusia serta dituntut untuk menghasilkan kualitas manusia yang lebih tinggi, huna menjamin pelaksanaan dan kelangsungan pembangunan.

Dengan melakukan kegiatan Educhild maka diharapkan dapat membantu murid - murid sekolah yang ada di Desa Bulak. Manfaat yang dapat diperoleh dengan kegiatan pembelajaran ini adalah dapat meningkatkan pemahaman murid - murid sekolah yang ada di Desa Bulak terhadap materi yang diajarkan di sekolah masing - masing.

\section{Metode}

\section{a. Persiapan}

Pada tahap persiapan, terdapat beberapa hal yang harus dilakukan. Seperti (1) membentuk panitia dan menentukan anggota yang akan 
melakukan kegiatan mengajar, (2) mencari tempat yang akan digunakan untuk tempat mengajar, (3) meminta ijin dari ketua RT dan RW sekitar untuk mengajar, (4) membuat jadwal mengajar yang akan dilakukan, dan (5) melakukan sosialisasi dengan warga mengenai kegiatan yang akan dilakukan.

\section{b. Pelaksanaan}

Tahap ini dimulai dengan melaksanakan kegiatan yang telah direncanakan sebelumnya. Meliputi (1) pembukaan, (2) mengelompokkan siswa berdasarkan usia \& kelas (TK, SD, SMP). Pengelompokkan bertujuan untuk memudahkan siswa agar lebih fokus dan dapat belajar sesuai tingkat pendidikannya, (3) melakukan pembelajaran sesuai kelas, (4) melakukan permainan interaktif yang berhubungan dengan pengetahuan umum.

\section{c. Penutupan}

Seusai melakukan kegiatan, panitia melakukan penutupan berupa games. Hal ini karena menurut Beck dan Wade dalam buku Harsono [1] juga menjelaskan bahwa games merupakan salah satu kegiatan untuk menarik perhatian peserta didik. Setelah melakukan kegiatan games diteruskan dengan kegiatan do'a bersama serta ucapan terima kasih kepada siswa dan ketua RT/RW yang telah meluangkan waktu mengikuti kegiatan yang rutin diadakan hingga selesai serta menyediakan tempat untuk melakukan kegiatan belajar mengajar.

\section{d. Evaluasi}

Evaluasi dari rangkaian kegiatan yang dilakukan meliputi (1) evaluasi rutin, yang dilakukan diakhir setiap sesi pembelajaran, mengenai kendala, timbal balik dari siswa kepada pengajar serta rencana materi untuk pengajaran selanjutnya, (2) evaluasi terakhir, dilakukan diakhir kegiatan. Bertujuan untuk menampung kritik dan saran dari panitia, anggota, maupun masyarakat yang terlibat mengenai kegiatan yang dilakukan, dari proses persiapan hingga penutupan. Baik berupa aspek positif maupun kekurangan dari kegiatan agar nantinya jika ada kegiatan serupa dapat dilakukan dengan lebih baik lagi.

\section{e. Pemantauan dan Evaluasi Kegiatan}

Kegiatan ini dilakukan oleh Himpunan Mahasiswa Manajemen Bisnis yang diamanahkan kepada departemen Sosial dan Masyarakat. Sehingga pemantauan kegiatan dilakuakn oleh presidium Himpunan yang beranggotakan ketua himpunan, wakil ketua, dan ketua departemen Himpunan Mahasiswa Manajemen Bisnis periode 2018/2019. Dengan adanya kegiatan evaluasi rutin maka kejadian yang tidak diinginkan dan dapat mengganggu kegiatan belajar mengajar dapat diminimalisir atau dicegah. Evaluasi juga menampung saran untuk kegiatan baru agar siswa tidak merasa bosan dalam belajar. Anggota panitia sebagai pengajar juga dapat fleksibel untuk memenuhi permintaan siswa mengenai materi yang diajarkan (materi baru, mengulang materi yang belum dipahami siswa, ataupun materi yang akan diujikan disekolah). Evaluasi juga melihat 
apakah pembelajaran yang dilakukan berdampak positif kepada siswa. Hal ini dapat dilihat dari peningkatan nilai ujian harian siswa yang mengikuti kegiatan belajar mengajar bersama Himpunan Mahasiswa Manajemen Bisnis.

\section{Hasil}

Kegiatan Educhild yang telah dilaksanakan oleh Divisi Sosial Masyarakat Prodi Manajemen Bisnis PPNS membuat anak - anak di Desa Bulak menjadi lebih teredukasi mengenai mata pelajaran yang diajarkan di sekolah berkat kegiatan ini. Selain itu, dengan diadakannya kegiatan Educhild dapat membuat anak - anak di Desa Bulak lebih aktif, kreatif serta komunikatif. Sehingga anak - anak di Desa Bulak menjadi terlatih mentalnya untuk menjadi anak yang pemberani. Seperti berkomunikasi dengan orang baru dan lebih aktif di kelas.

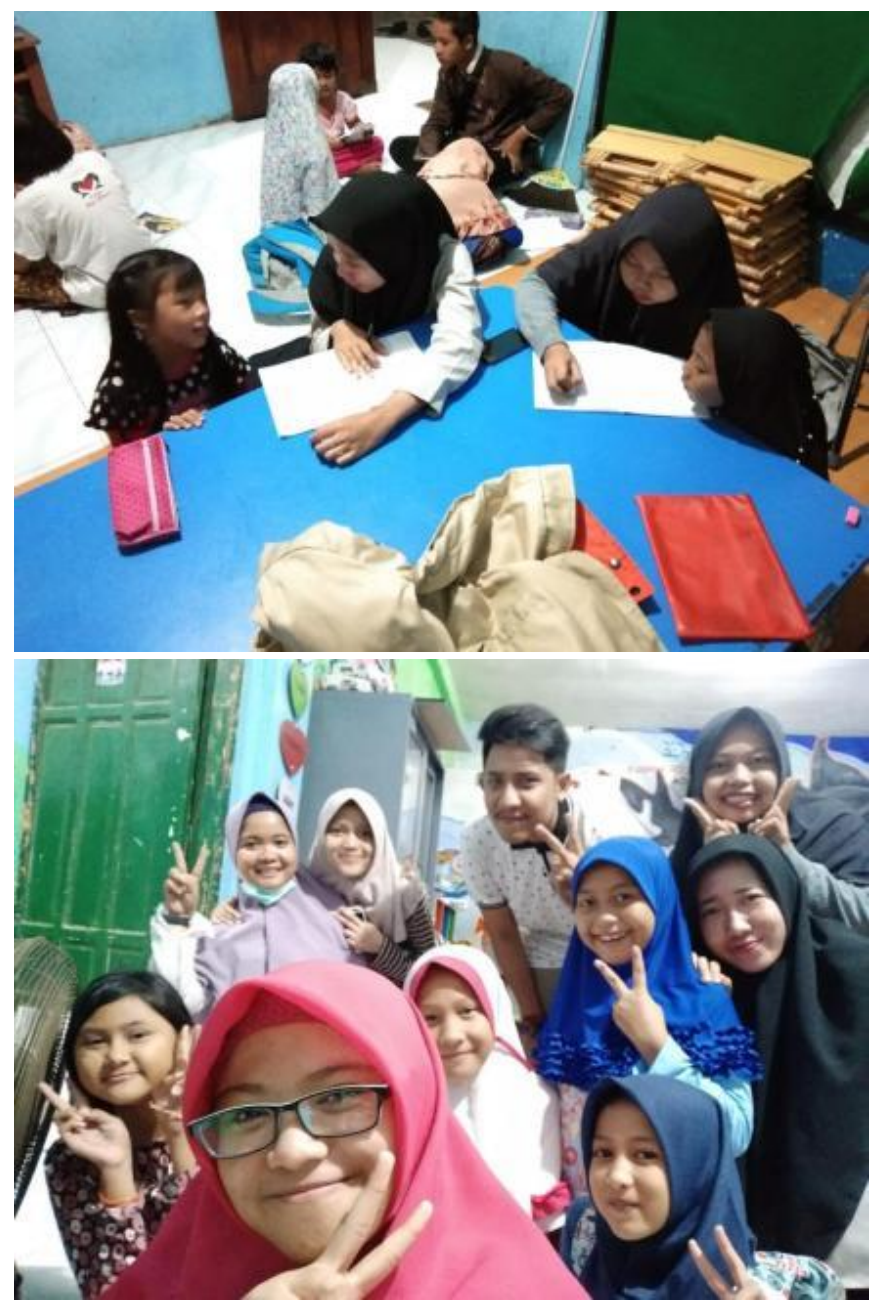

Gambar 1 : Dokumentasi kegiatan Educhild di Desa Bulak

Pada kegiatan Educhild tersebut diikuti oleh banyak siswa dan siswi dari berbagai kelas. Pengajar dibagi berdasarkan tingkatan kelas para siswa dan siswi. Selain itu jumlah pengajar juga ditentukan berdasarkan jumlah siswa tetap yang mengikuti kegiatan ini. Pengajar diberikan jadwal mengajar sesuai jadwal yang telah dibuat dan waktu yang telah disusun sebelumnya berdasarkan kesepakatan bersama antar pengajar. 


\section{Pembahasan}

Pelaksanaan kegiatan pengabdian berupa pengajaran kepada siswa Taman Kanak-Kanak, Sekolah Dasar, dan tingkat Sekolah Menengah Pertama dengan nama kegiatan educhild. Kegiatan educhild merupakan salah satu program kerja Departemen Sosial Masyarakat Himpunan Mahasiswa Manajemen Bisnis Politeknik Perkapalan Negeri Surabaya periode 2018-2019. Kegiatan edichild diawali dengan persiapan yang terkait dengan perizinan, rangkaian kegiatan, dan penjadwalan kegiatan. Setelah tim memperoleh izin dari pihak Desa Bulak, maka dilakukan penentuan rangkaian kegiatan yang terdiri atas Pembukaan, kegiatan pengajaran, dan penutupan. Selanjutnya yaitu penentuan jadwal megajar. Acara ini terselenggara selama 3 bulan pada bulan September hingga Desember 2018 dengan pertemuan satu kali dalam seminggu pada hari Rabu pada jam 18.30-20.00. Jumlah pengajar 50 orang dengan pembagian setiap sesi pertemuan adalah 15 orang. Kegiatan ini diikuti kurang lebih 40 pelajar. Pola pengajaran yang digunakan adalah seperti terlihat pada gambar 4.1 sebagai berikut

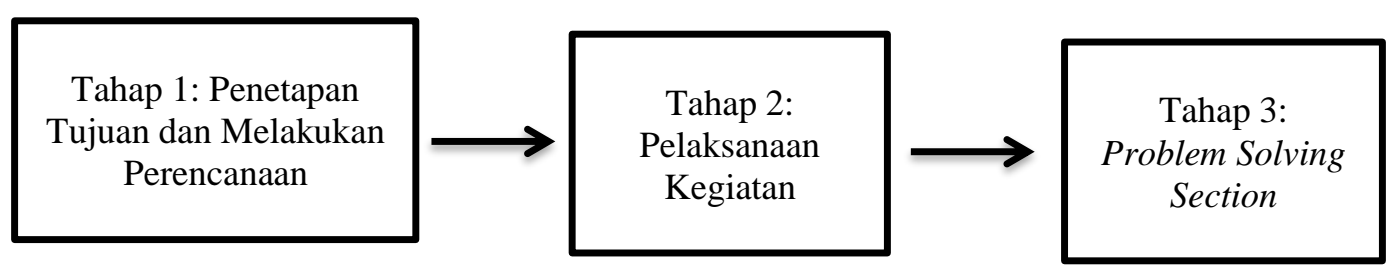

Gambar 2 Pola Pengajaran

Penjelasan mengenai pola pengajaran tersebut adalah sebagai berikut:

a. Penetapan Tujuan dan Melakukan Perencanaan

Anggota tim menentukan gambaran/wawasan tentang kegiatan yang akan dilaksanakan dan merencanakan kegiatan pembelajaran secara kolaboratif. Perencanaan pembelajaran didesain untuk mewujudkan tujuan.

b. Pelaksanaan Kegiatan

Anggota tim pengajar melakukan kegiatan pengajaran di kelas sesuai dengan bagiannya masing-masing .

c. Problem Solving Section

Pelajar dapat menanyakan kesulitan pelajaran yang dirasakannya dan tim pengajar wajib memberi solusi atas permasalahan tersebut dengan pembahasan yang mudah dipahami oleh pelajar.

Kegiatan educhild yang telah dilakukan telah memberikan hasil berupa adanya peningkatan aktivitas pelajar dalam belajar dan antusiasme pelajar dalam mengerjakan dan menyelesaikan tugas rumah yang sangat besar. Hail ini terlihat dari hasil observasi yang dilakukan oleh semua tim pengajar yang hadir di kelas ketika pembelajaran berlangsung. Siswa terlihat lebih aktif dan antusias dalam berkomunikasi, bertanya, menjawab, menyimpulkan, dan mengkomunikasikan temuannya. Hal ini tentu saja membuat kegiatan educhild menjadi lebih bermakna bagi siswa. Selanjutnya berdasarkan kegiatan yang telah dilakukan, beberapa pertanyaan atau masalah yang diajukan oleh pelajar 
dapat dipecahkan melalui kegiatan pada tahap 1 yaitu Penetapan Tujuan dan Melakukan Perencanaan dan tahap 3 yaitu Problem Solving Section . Hal ini dapat dipahami karena pada tahap 1 dan tahap 3 merupakan tahap yang dapat dilakukan dengan hasil akhir yang efektif dan efisien yang dapat membuat pelajar paham dan mengerti atas jawaban atas pertanyaannya. Perencanaan akan lebih matang bila disertai dengan saran serta masukan yang berharga dan diakomodasi dengan baik dalam tim dan langsung diimplementasikan dalam bentuk perbaikan pembelajaran.

\section{Kesimpulan}

Kegiatan pengajaran yang telah dilakukan di Desa Bulak Kota Surabaya bisa meningkatkan kualitas proses pembelajaran. Kegiatan ini memberikan hasil berupa adanya peningkatan aktivitas pelajar dalam belajar dan antusiasme pelajar dalam mengerjakan dan menyelesaikan tugas rumah yang sangat besar. Siswa terlihat lebih aktif dan antusias dalam berkomunikasi, bertanya, menjawab, menyimpulkan, dan mengkomunikasikan temuannya. Selain itu adanya dukungan oleh seluruh anggota tim terhadap usulan yang diajukan untuk perbaikan kegiatan semakin menambah keyakinan bahwa educhild merupakan salah satu program solusi dari beberapa permasalahan yang terkait dengan berkomunikasi, bertanya, menjawab, menyimpulkan, dan mengkomunikasikan temuannya.

\section{Ucapan terima kasih}

Ucapan terimaksih diberikan kepada semua pihak yang berkontribusi dan mendukung terlaksananya kegiatan Educhild di Desa Bulak yaitu :

1. Politeknik Perkapalan Negeri Surabaya

2. Himpunan Mahasiswa Manajemen Bisnis Politeknik Perkapalan Negeri Surabaya Periode 2018-2019

3. Masyarakat Desa Bulak yang berkontribusi dalam kegiatan Educhild

\section{Daftar pustaka}

[1] Brama Jolinanda, "Motif Siswa MAN 2 Padang Memilih Les Private sebagai Sarana untuk Memperoleh Pembelajaran Tambahan," 2016.

[2] Ma'ruf Harsono, "Pengaruh bermain game terhadap perkembangan remaja," Surya University, 2014.

[3] Undang-Undang No.12 Tentang Pendidikan Tinggi, 2012. 